\title{
Artigo
}

\section{A primazia de Wall Street e a continuidade dos privilégios do setor financeiro no governo Trump}

\author{
The primacy of Wall Street and the continuity of financial sector privileges on \\ Trump administration
}

Eduardo Santos Maia ${ }^{1}$

DOI: $10.5752 /$ P. 1809-6182.2017v14.n3.p23

Recebido em :10\08\2017 Aprovado em: 23\01\2018

\section{Resumo}

O presente trabalho abordará a continuidade da primazia dos interesses de Wall Street no governo Trump. Um exame do processo de financeirização iniciado na década de 1970 será feito, a partir de um voo panorâmico sobre as medidas adotadas pelos governos norte- americanos desde então, a fim de evidenciar o caráter histórico da inserção das finanças na Casa Branca. Segue-se a análise da relação entre Wall Street e a administração Trump, marcada pelas iniciativas adotadas pelo presidente estadunidense em favor do setor financeiro. Para tanto, foi feita pesquisa bibliográfica qualitativa que dialogasse com a questão em diferentes momentos (TAVARES, 1985; GILL, 2000; PANITCH e GINDIN, 2013), além de consultas a midia e discursos oficiais. A pesquisa conclui pelo aumento da projeção de interesses do setor financeiro na esfera politica pela adoção de medidas favoráveis a Wall Street, como os avanços no desmonte da Lei Dodd-Frank e a suspensäo da "regra fiduciária", e pela continuidade da relação imiscuida entre as partes.

Palavras-chave: Wall Street; governo Trump; desregulaçâo financeira

\begin{abstract}
The present paper discusses the continuity of the primacy of Wall Street interests on Trump administration. An exam of the process of financialization initiated in the 1970s will be made, overviewing the measures adopted by the American presidents since then, in order to demonstrate the historical character of the insertion of finance in the White House. Thereafter, it follows an analysis of the Wall Street-Trump administration relation, characterized by initiatives from the President in favor of the financial sector. For this purpose, it was conducted a qualitative bibliographic research, in dialog with the subject throughout different moments (TAVARES, 1985; GILL, 2000; PANITCH \& GINDIN, 2013), as well as searches in the media and official discourses. The paper concludes by the rise of the projection of financial sector interests on the political sphere, both by the adoption of favorable measures to Wall Street, as advances on the revoke of Dodd-Frank Act and the suspension of the "fiduciary rule", and the permanence of the meddling relation between Washington and Wall Street.
\end{abstract}

Key words: Wall Street; Trump administration; financial deregulation

1. Mestre em Economia Política Internacional, bacharel em Relaçôes Internacionais, ambos pela Universidade Federal do Rio de Janeiro. ORCID: orcid.org/0000-0002-9347-8841 


\section{Introdução}

A eleição de Donald Trump para a presidência dos Estados Unidos foi uma grande surpresa no meio político. Sua campanha de Trump foi marcada pela "pós-verdade" e pela hostilidade a setores críticos. Trump foi capaz de pavimentar seu caminho para a Casa Branca ao proclamar combater as supostas ameaças ao cidadão estadunidense - o desemprego e os imigrantes - enquanto atacava grupos de pouco apelo popular, em especial o jornalismo e o setor financeiro. Em relação ao segundo grupo, as promessas de imposição de maior rigidez, aumento na taxação sobre a especulação e redução do poder da elite financeira tiveram grande apelo a uma classe média que identificava a ganância de Wall Street, e a crise advinda dela, como uma das causas principais da estagnação de seus salários.

O governo Trump, de fato, tem se apresentado diferente das gestōes anteriores em diversos aspectos. No entanto, a dinâmica entre poder político e poder financeiro continua como um dos pilares da economia política dos Estados Unidos. Seabrooke (2001) conceptualiza a natureza das instituiçóes estadunidenses e sua relação com o setor financeiro em termos de uma "integração embutida" que se refere a simultânea relação de cooperação e competitividade entre o Estado e as finanças norte-americanas.

Tavares (1985) identificou a imiscuiçấo de Wall Street em Washington como característica fundamental da continuidade hegemônica dos Estados Unidos. Para a autora, não há como dissociar o poder dos Estados Unidos do poder de seu setor financeiro, bem como não há separação - à exceção de momentos pontuais de dissonância - entre os interesses de ambas as partes. Em outras palavras, a projeção internacional de poder dos Estados Unidos passa pela projeção de seu setor financeiro. Para Panitch e Konings (2008), a financeirização em escala global possibilitou o estabelecimento de uma "base imperial" ao renovar o dólar como "fulcro do sistema financeiro internacional".

A partir de ângulos diferentes ambos os argumentos dialogam com a dinâmica de poder estrutural apresentada por Strange (1988a), particularmente no entendimento do aspecto financeiro como uma das estruturas fundamentais do exercício do poder e da política. O aprofundamento da relaçâo Estado-finanças se deu com a financeirização da economia estadunidense - e mundial - iniciada na década de 1970 e consolidada na década seguinte. Zwan (2014) apresenta a financeirização no período como uma rede de processos inter-relacionados - econômicos, políticos, sociais, tecnológicos - através da qual o setor financeiro expande sua influência para além do mercado e da economia.

Embora o processo de financeirização tenha se desacelerado, seus reflexos subsistem. A primazia do setor financeiro é uma constante nos diferentes governos desde então. A mudança de perfil presidencial não resultou em mudanças na dinâmica de sujeição da economia política de Washington aos interesses de Wall Street.

\section{A (re) ascensão das finanças}

O rompimento unilateral do governo dos Estados Unidos com Bretton Woods e o regime cambial fixo é o marco inicial para o processo de financeirização da economia internacional nas décadas seguintes. $\mathrm{O}$ fim da conversibilidade entre ouro e dólar, e a consequente flexibilidade conferida a moeda norte-americana, representou liberdade de ação para Washington e possibilidade de projeção internacional para Wall Street.

A liberdade para fazer flutuar o dólar é assim uma das vantagens do padrão dólar flexível, que permite que os Estados Unidos náo tenham que perder competitividade real em nome da manutençâo de sua preeminência 
financeira e monetária. A outra vantagem para os Estados Unidos da ausência de conversibilidade em ouro é a eliminação pura e simples de sua restrição externa. (SERRANO, 2002, p.251)

A difusão do poder estadunidense através do dólar se deu pelo ganho geopolítico na crescente disputa intercapitalista e pela projeção de seu capital financeiro. O período que se sucedeu ao fim do regime de câmbio fixo foi marcado pela progressiva migração dos países em direção a sistemas financeiros nacionais cuja única preocupação era resistir aos fluxos de capitais desregulamentados. A necessidade dos países de restaurar a confiança do mercado por meio de programas de austeridade e incentivos à entrada de capitais, principalmente o capital financeiro, permitiu aos Estados Unidos enquadrar todas as partes do sistema financeiro internacional à dinâmica da sua moeda e de suas finanças.

Houve iniciativas que buscaram reverter o quadro de subordinação dos Estados aos mercados, e consequentemente, às finanças estadunidenses, porém nenhuma foi bem-sucedida (HELLEINER, 1996). As principais tentativas partiram da Inglaterra e da França e embora eventos internos tenham sido relevantes para o fracasso de ambas iniciativas, foi a pressão norte-americana pela expansão da financeirização do sistema internacional o principal elemento que inviabilizou qualquer movimento no sentido contrário à projeção de poder norte-americana, via financeirização do sistema. As finanças, agora epicentradas nos Estados Unidos, voltaram a ser o centro da economia política internacional pela primeira vez desde a década de 1920.

O fim de Bretton Woods deu início a uma nova era do sistema financeiro internacional. $\mathrm{O}$ sistema financeiro norte-americano catapultado pela II Guerra Mundial e fortalecido nas décadas seguintes, mesmo sob a rigidez do controle de capitais exercida durante o sistema de câmbios fixos, finalmente pôde assumir dimensões internacionais. $\mathrm{O}$ que se seguiu foi, naturalmente, o prolongamento e o aprofundamento da proeminência das finanças norte-americanas (PANITCH; GINDIN, 2005, 2013).

O segundo ponto de inflexão da nova dinâmica do sistema financeiro internacional foi o choque de juros promovido pelo Federal Reserve sob o comando de Paul Volcker em 1979. Uma das consequências do aumento das taxas de juros praticadas pelos Estados Unidos foi a drenagem dos investimentos internacionais. A combinação da alta credibilidade e - relativamente - alta remuneração oferecida pelos títulos públicos estadunidenses transformou o mercado financeiro norte-americano no ponto de convergência para o capital a ser investido no mundo. Para os demais países, representou escassez de dólares, estagnação e aumento da dívida pública, no caso de países com dívidas em dólar.

A política monetária restritiva aplicada por Washington era consoante com o fortalecimento das finanças como eixo central da economia política estadunidense. $\mathrm{O}$ primado das finanças passou a ser elemento central na lógica político-econômica, desde a pressão exercida sobre a União Soviética até a reestruturação pós-crise de 2008 . O governo Reagan foi o caso mais emblemático dessa nova dinâmica. A década de 1980 foi de aprofundamento dos laços entre o poder público e as finanças, a desregulação dos sistemas bancário e financeiro e a desoneração das grandes empresas do setor financeiro foram os pontos principais dessa etapa (HELLEINER, 1996). A face financeira foi a principal vertente do neoliberalismo implementado por Reagan.

Nas administraçóes seguintes o setor financeiro permaneceu como um dos eixos principais $\mathrm{da}$ economia política. A associação da família Bush com o setor financeiro - ambos os presidentes da 
linhagem trabalharam para o Carlyle Group ${ }^{2}$ - se refletiu nas políticas adotadas ao longo dos doze anos somados de governo. A aprovação de leis regulatórias como resposta à crise especulativa do início dos anos 2000 pode passar a falsa impressão de retrocesso no processo de liberalização financeira; no entanto, o que de fato ocorreu foram novas rodadas de desregulação e incentivos ao setor financeiro.

A permissividade com os chamados shadow banks no período é tratada como uma das causas fundamentais da crise financeira de 2008 (BERNANKE, 2010). A centralidade das finanças no governo de George W. Bush pode ser identificada também na principal divisa de seu governo: a Guerra ao Terror. Pela primeira vez, uma guerra ganhou contornos financeiros, paralelamente às ações manu militari, situação que passou a ser recorrente nos conflitos seguintes, particularmente durante a administração Clinton (BASILE, 2004).

Afirma-se comumente que os republicanos possuem maior tendência de apoio ao grande empresariado e ao setor financeiro. No entanto, Bill Clinton foi responsável pela reorientação ideológica de seu partido a partir do Democratic Leadership Counci $\beta$, que representou o afastamento dos estratos menos favorecidos e aproximação de Wall Street e das grandes empresas pelos democratas (BEHAN, 2016). Nos anos Clinton também ocorreram rodadas de desregulação financeira, com destaque para a aprovação da Lei de Modernização dos Serviços Financeiros (1999), que revogou a legislação de Glass-Steagall, um marco da regulação anticrise financeira vigente desde 1933. A partir de então voltou a ser legal a combinação de bancos comerciais, de investimento e seguradoras, em essência insti-

2. Um dos maiores grupos de private equity e leveraged buyout do mundo, um conglomerado de investimentos essencialmente financeiros.

3. Organização sem fins lucrativos fundada em 1985 por lideranças do Partido Democrata, cujas principais bandeiras eram o abandono do "populismo econômico" e a busca por uma "terceira via" alternativa à dicotomia esquerda e direita. tuições financeiras agora voltaram a utilizar fundo dos depositantes para especulações no mercado de ações. Cintra (1998) identifica a substituição de bancos pequenos por bancos de grande porte nas décadas de 1980 e 1990 como consequência do desmonte das condições estruturantes do sistema monetário-financeiro norte-americano, que privilegiaram grandes corporaçôes financeiras.

Ambas as administraçôes Obama se iniciaram com a promessa de romper a estrutura viciosa de Wall Street. No entanto, no primeiro mandato, Obama deu continuidade à política de salvamento dos bancos iniciada por Bush. A oposição popular a Wall Street na esteira da crise de 2008 demandou que Washington adotasse medidas que contivessem a influência do setor financeiro e, nesse sentido, Obama foi capaz de aprovar a lei Dodd-Frank. "The Dodd-Frank Act arose from anger and cries for retribution against Wall Street" (ACHARYA et al, 2010, p.12). Porém, Wooley e Ziegler (2011) interpretam a lei Dodd-Frank como uma ação clara por parte do poder Executivo para manter a continuidade entre as organizações e elites do setor financeiro. Não houve uma ruptura em relação ao que existia anteriormente, mas a adição de uma nova camada, que alterou aspectos secundários do sistema financeiro norte-americano sem promover mudanças em aspectos centrais ou deslegitimar o regime existente.

No segundo mandato, seguindo a esteira do movimento "Occupy Wall Street" (OWS), a retórica de enfrentamento ao setor financeiro foi ainda mais forte. DeLuca, Lawson e Sun (2012) investigaram a relação - real e projetada - entre Obama e o OWS e identificaram o uso da popularidade do movimento na campanha de reeleição. A "acusação" de participação de Obama no movimento foi estimulada pela equipe de Obama a fim de se criar no imaginário da população uma associação entre os princípios defendidos pelo movimento e aqueles de Obama em 
relação aos banqueiros. Buscou-se, assim, distanciar Obama da representaçấo de Wall Street. Na prática, o financiamento da campanha presidencial em 2011 recebeu mais doaçóes advindas de empresas do setor financeiro do que qualquer outra: aproximadamente $20 \%$ do total recebido por Obama se deu pelas empresas Goldman Sachs, AIG, Morgan Stanley, JP Morgan Chase, Bank of America e Citigroup (SCARBOROUGH, 2011).

Observa-se que, desde a virada financeira iniciada na década de 1970, os diferentes governos, independentemente dos matizes ideológicos que os sustentaram, interiorizam em Washington os interesses de Wall Street. Faz-se necessário ressaltar que a relação Estado e capital norte-americano é mais complexa, o conceito de Fiori (2004) de poder global ganha dimensão analítica ao se entender o estímulo do Estado ao capital financeiro como mecanismo de estruturação de poder, processo mutuamente vantajoso. É importante ainda não desconsiderar as diferenças estruturais entre as presidências norte-americanas, porém reconhecer a aplicação dos interesses do setor financeiro ao longo de distintas administrações. O governo de Donald Trump, por sua vez, não tem sido diferente. Se, por um lado, é possível afirmar que a política vem sendo exercida de forma diferente na Casa Branca; por outro, os privilégios de Wall Street permanecem centrais na execução da economia política dos Estados Unidos.

\section{A primazia de Wall Street sob Trump}

A dinâmica político-econômica da relação entre o governo norte-americano e Wall Street pode ser entendida a partir do conceito de "nexo Estado-finanças” apresentado por David Harvey (2011),

[O nexo Estado-finanças] descreve a confluência do poder estatal e das finanças que rejeita a tendência analítica de ver o Estado e o capital como claramente separáveis um do outro. Isso não significa que o Estado e o capital tenham constituído no passado ou agora uma identidade, mas que existem estruturas de governança nas quais a gestáo do Estado para a criação do capital e dos fluxos monetários torna-se parte integrante, e não separável, da circulação do capital. A relação inversa também se sustenta na medida em que impostos ou empréstimos fluem para os cofres do Estado e na medida em que as funções do Estado também se monetarizam, mercantilizam e, finalmente, privatizam (HARVEY, 2011, p.47-8).

O governo Trump não foge à regra, a presença de Wall Street no exercício político conserva-se como componente basilar da administração do republicano no primeiro ano de seu governo. A eleição de Trump foi marcada por acalorada campanha contra os desmandos do setor financeiro, no que se efetivou como uma mudança significativa de posiçấo da atual presidência. Em comercial de campanha, Trump denunciou Wall Street como "a global power structure that is responsible for the economic decisions that have robbed our working class, stripped our country of its wealth and put that money into the pockets of a handful of large corporations". No entanto, de acordo com o Center for Responsive Politics, organização que analisa doaçóes políticas, o discurso anti-rentista e a retórica de taxaçáo sobre Wall Street se converteu no recebimento de 5 milhóes de dólares de empresas do ramo financeiro.

Apesar do discurso populista de oposição a Wall Street, o que efetivamente vem sendo posto em prática é a continuidade da facilitação financeira assegurada pelo governo norte-americano. Verifica-se, portanto, aprofundamento do "novo constitucionalismo" apresentado por Gill (2000), em que se destacam novas formas de relaçóes entre mercado e Estado, com uma governança maior do primeiro sobre o segundo, que resulta no empoderamento 
dos mercados internacionais financeirizados frente tanto ao Estado quanto à sociedade.

A crise do subprime momentaneamente dificultou a posiçáo de Wall Street junto a Casa Branca. Não obstante, a superação da crise, a alternância de governo e, principalmente, a mudança dos temas prioritários debatidos em âmbito público possibilitaram que Wall Street voltasse a pleitear novas rodadas de desregulação. Nesse sentido, Trump tem sido eficaz em definir a agenda de debate político. Assuntos historicamente abordados com destaque como a conjuntura econômica ou as políticas monetária e fiscal deram lugar a temas igualmente importantes, porém mais receptivos à abordagem superficial adotada pelo presidente, tais como a imigração e a posição dos Estados Unidos no cenário mundial. Como consequência, a discussão da relação Wall Street-Washington, marcante em governos anteriores, é relegada a segundo plano, ausente do debate popular e da mídia em processo que facilita a justaposição acrítica dos interesses do setor financeiro na esfera política.

O programa econômico apresentado pela equipe de Trump remonta às decisóes tomadas por Reagan para a recuperação econômica do país. Da mesma forma que na década de 1980, afirma-se que a redução da taxação sobre lucros financeiros e ganhos de capital é uma forma eficaz de estímulo à economia. Assim, Trump pretende reduzir a alíquota máxima de imposto para pessoa jurídica de $35 \%$ para 15\%. De acordo com o Secretário do Tesouro, Steven Mnuchin: "This is going to be the biggest tax cut and the largest tax reform in our history". (CNN,2017)

A administraçáo Trump, permeada de nomes originários de grandes instituições financeiras ${ }^{4}$, tem advogado em favor da principal bandeira de Wall

4. Steve Bannon para o cargo de estrategista-chefe da Casa Branca; Steve Mnuchin para Secretário do Tesouro e; Gary Cohn para conselheiro econômico-chefe da Presidência.
Street: a desregulação financeira. De forma coerente, as propostas pró-Wall Street gravitam em torno da abolição da "anti-growth regulation" e o estabelecimento de "new modern regulatory framework", que, na prática, se traduzem na remoção de barreiras à reproduçáo do capital financeiro. Logo nos primeiros meses, Trump concedeu a Wall Street sua primeira grande vitória com a suspensão da "regra fiduciária”, que determinava normas para os administradores de pensão. Enquanto a regra vigorou, os bancos eram obrigados a agir conforme o melhor interesse do cliente e não apenas de acordo com a maior rentabilidade para a instituiçáo. As instituições financeiras alegam que a legislação aumenta os custos operacionais, que são repassados ao cliente, encarecendo o serviço. A favor da regra há o entendimento da mesma como um meio de proteção do consumidor a fim de prevenir que instituiçôes financeiras se aproveitem de clientes e especulem com o dinheiro das contribuiçóes.

Concomitante à suspensão da "regra fiduciária" e outras investidas menores, uma das principais causas reivindicadas por Wall Street é a reversão da legislação Dodd-Frank, documento de cerca de 2300 páginas que define regras mais rígidas para o setor financeiro. Aprovada em 2010, foi uma reação do Congresso à crise de 2008, quando o governo precisou intervir injetando bilhões de dólares para salvamento dos bancos. Seu objetivo central é evitar novos choques econômicos de origem financeira. A legislação estabeleceu regras destinadas a impedir a repetição dos passos da crise de 2008, tratando desde a supervisão das instituiçôes financeiras até o fim do conceito "too big to fail".

A Lei também fez mudanças substanciais na regulamentação de derivativos de balcão, introduziu exigências de capital regulatório mais rigorosas, implementou mudanças na remuneração de executivos e práticas de governança corporativa, reformou a regulamentação das agências de classificação de risco e 
incorporou a chamada Regra Volcker. e fez grandes mudanças no mercado de securitização. (KAAL, 2016, p.1,tradução nossa) ${ }^{5}$.

No entanto, Wilmarth (2011) aponta que a lei Dodd-Frank não foi suficiente para cumprir suas funçóes. O autor caracteriza a lei como "inadequada" e "falha". Sua análise destaca que a lei reforça apenas modestamente os limites de operação dos grandes agentes financeiros e mantém a possibilidade de salvamento dos bancos ao prever resoluçóes especiais a partir do novo conceito de "instituiçôes financeiras sistemicamente importantes". "Barack Obama e seus conselheiros decidiram que esses [as instituições financeiras sistemicamente importantes] eram os bancos sobre os quais depende a prosperidade econômica do país" (JOHNSON e KWAK apud CEZAR, 2015, p.58). Em outras palavras, mesmo o ponto central da lei Dodd-Frank não toca na estrutura da relação privilegiada do setor financeiro com a política.

Mesmo diante do pequeno impacto potencial da nova legislação, desde sua aprovação o setor financeiro tem buscado mitigar sua efetividade.

A ação das indústrias do setor [financeiro] é bastante clara desde a entrada em vigor da Dodd-Frank. Não sendo possível buscar a revogação imediata da lei, as indústrias do setor têm combatido uma regra após a outra, usando o contato privilegiado que detêm com as agências regulatórias em seu favor e, em última instância, levantando questóes procedimentais em corte, especialmente no que tange a necessidade de se fazerem análises de custobenefício das regras em voga, algo que atrasa e por vezes inviabiliza a sua implementação de fato (CEZAR, 2015, p.57).

Nesse sentido, a "luta" do setor financeiro encontrou eco em Trump. $\mathrm{O}$ atual presidente tem se

5. The Act also made substantial changes in over-the-counter derivative regulation, introduced tougher regulatory capital requirements, implemented changes in executive compensation and corporate governance practices, reformed regulation of risk rating agencies, and incorporated the so-called Volcker Rule. and made major changes in the securitization market. mostrado favorável a retirada das pequenas limitaçóes impostas pela lei Dodd-Frank. A perspectiva de Trump sobre a reversão da lei Dodd-Frank vai ao encontro dos interesses de Wall Street.

Esperamos cortar muito do Dodd-Frank, porque, francamente, tenho muitas pessoas, meus amigos que tiveram bons negócios, não podem pedir dinheiro emprestado. Eles simplesmente não conseguem dinheiro porque os bancos simplesmente não os deixam pedir emprestado por causa das regras e regulamentos em Dodd-Frank..(PROTESS Ben; HIRSCHFELD Julie, 2017, tradução nossa). ${ }^{6}$

$\mathrm{O}$ argumento alegado por Trump, no entanto, é simplório, se resumindo à lógica superficial de que com a desregulação do setor bancário os bancos emprestarão mais, movimentando a economia. Tal lógica desconsidera elementos inerentes ao setor financeiro, em outras palavras, sem regulação, os bancos não necessariamente revertem suas reservas para o crédito ao público. A experiência da década de 1980 demonstrou que as instituições financeiras tendem a investir o acumulado em novas aplicações financeiras que proporcionam maior lucratividade, em processo inteiramente descolado da esfera produtiva.

A desestruturação da lei é altamente desejável por Wall Street. Apenas a ordem executiva de Trump para início do processo de reversão da lei Dodd-Frank aumentou o valor das açóes dos principais bancos americanos em mais de 2\%. Já a Goldman Sachs, anunciada como vilã em campanha, atingiu o maior valor acionário de sua história, devido tanto a sua integração informal com a Casa Branca, quanto às políticas recentes favoráveis que melhoram as perspectivas de aumento do lucro. Com maioria na Câmara e no Senado, Trump e os republicanos podem reverter ao menos parte da lei.

6. We expect to be cutting a lot out of Dodd-Frank, because frankly, I have so many people, friends of mine that had nice businesses, they can't borrow money. They just can't get any money because the banks just won't let them borrow it because of the rules and regulations in Dodd-Frank. 
A tendência é de continuidade do impulso à financeirização. Não somente na análise do governo Trump, mas também quando observado o histórico das últimas quatro décadas da economia política norte-americana. A administração de Trump trilha o mesmo caminho das gestóes anteriores ao dar continuidade a primazia dos interesses de Wall Street.

\section{Considerações finais}

Indiferente ao recorte temporal, o nexo Estado-finanças mantem-se no cerne da dinâmica político-econômica dos Estados Unidos. O processo de financeirização iniciado com o rompimento unilateral do sistema de Bretton Woods cristalizou-se ao longo da década de 1980 e se tornou parte indissociável da política praticada por Washington já a partir da década de 1990. Nesse sentido, o total de ativos financeiros americanos no mercado mais que duplicou em duas décadas, passando de 8,2\% em 1980 para 17,2\% em 2004 (BRAGA e CINTRA, 2004). Em análise quantitativa, Krippner (2005, p.199) conclui:

Ao sugerir que a trajetória da economia dos EUA nas últimas décadas é adequadamente caracterizada em termos de um processo de financeirização, minha alegação empírica central é de que a acumulação está ocorrendo cada vez mais através de canais financeiros. ${ }^{7}$

Nas últimas décadas os interesses de Wall Street têm sido projetados em Washington. A inserção de Trump na política provocou uma mudança de foco do debate político de temas como terrorismo e crises financeiras para outros, tais como imigração e a revisão de programas de saúde, porém não alterou o jogo de interesses de forma fundamental. A difi-

7. In suggesting that the trajectory of the US economy in recent decades is aptly characterized in terms of a process of financialization, my central empirical claim is that accumulation is now occurring increasingly through financial channels. culdade de reação frente a singularidade de Trump, bem como a promoção de temas não relacionados ao setor financeiro mascaram a dimensão com que as finanças adentraram na Casa Branca.

Particularmente na administração Trump, tem-se observado o aprofundamento dos laços entre o setor financeiro e a elite política. A hostilidade da campanha não se sustentou após a eleição. As iniciativas do republicano em favor da desregulação financeira são uma boa indicação do papel que terá o setor financeiro ao longo do governo. De forma coerente com o histórico das últimas décadas, a primazia de Wall Street permanece uma constante na administração Trump.

\section{Referências}

ANDERSON, Perry. A política externa norte-americana e seus teóricos. São Paulo: Boitempo Editorial, 2015.

BASILE, Mark. Going to the source: why Al Qaeda's financial network Is likely to withstand the current war on terrorist financing. Studies in Conflict and Terrorism, v. 27, n. 3, p.169-185, 2004.

BEHAN, Richard. The Clintons and Wall Street: 24 years of enriching each other. Counterpunch. Petrolia, 26 fev. 2016.

BELLUZZO, Luiz Gonzaga. Finança global e ciclos de expansão. In: FIORI, José Luís. Estados e moedas no desenvolvimento das naçóes. Petrópolis: Vozes, 2012.

BERNANKE Charman. Causes of the Recent Financial and Economic Crisis. Federal Reserve, Washington, 6 set. 2010. Disponível em:< https://www.federalreserve.gov/newsevents/ testimony/bernanke20100902a.htm>Acesso em: 30 ago. 2017.

BRAGA, José Carlos de Souza; CINTRA, Marcos Antonio Macedo. Finanças dolarizadas e capital financeiro: exasperação sob comando americano. In: FIORI, José Luís. O poder americano. Petrópolis: Vozes, p. 253-307. 2004.

CUNY, Delphine. Trump, Wall Street and the banks: Massive deregulation ahead, Euractiv,London, 15 nov. 2016.Disponível em: <https://www.euractiv.com/section/euro-finance/ news/trump-wall-street-and-the-banks-massive-deregulation-ahead/>. Acesso em: 07 ago. 2017.

DOMM, Patti. Bank stocks on pace for best day since November as Trump sets sights on financial deregulation,CNBC, New York, 3 feb. 2017. Disponível em: <https://www.cnbc. com/2017/02/03/bank-stocks-on-pace-for-best-day-since-november-as-trump-sets-sights-on-financial-deregulation.html> . Acesso em: 8 ago. 2017. 
EGAN, Mat. Goldman Sachs up 37\% since Trump's election,CNN, Atlanta, 14 feb. 2017. Disponível em: <http://money.cnn.com/2017/02/14/investing/goldman-sachs-stock-record-high-dodd-frank/index.html>. Acesso em: 8 ago. 2017.

EICHENGREEN, Barry. Exorbitant Privilege: The rise and fall of the dollar. Oxford: Oxford University Press, 2011.

FIORI, José Luís. Estados, Moedas e Desenvolvimento. In: FIORI, José Luís. Estados e moedas no desenvolvimento das naçôes. Petrópolis: Vozes, 2012.

FIORI, José Luís. O poder americano. Petrópolis: Vozes, 2004.

GILL, Stephen. American hegemony and the Trilateral Comission. Cambridge: Cambridge University Press, 1990.

GILL, Stephen. The constitution of global capitalism. In: The capitalist world, past and present at the International Studies Association Annual Convention, Los Angeles. The Global Site, p.1-20, 2000.

HARVEY, David. O enigma do capital e as crises do capitalismo. São Paulo: Boitempo Editorial, 2011.

HELLEINER, Eric. States and the reemergence of global finance: From Bretton Woods to the 1990s. Nova Iorque: Cornell University Press, 1996.

KAAL, Wulf. Dodd-Frank Act. In: FARAZMAND, Ali. Global encyclopedia of public administration, public policy, and governance. [s.l.]: Springer International Publishing, p. $1-5,2016$.

KRIPPNER, Greta. The financialization of the American economy. Socio-economic Review, v. 3, n. 2, p.173-208, mai. 2005.

LONG, Heather. Trump has done a big flip-flop on Wall Street,CNN,Atlanta, 26 apr. 2017 Disponível em: <http:// money.cnn.com/2017/04/26/investing/donald-trump-wall-street/index.html> Acesso em: 7 ago 2018.

OPEN SECRETS. Donald Trump, Washington, 2016. Disponível em: <https://www.opensecrets.org/pres16/candidate?i$\mathrm{d}=\mathrm{n} 00023864>$. Acesso em: 12 nov. 2017.

PANITCH, Leo; GINDIN, Sam. Finance and American Empire. Socialist Register, Londres, v. 41, p.46-81, 2005.

PANITCH, Leo; GINDIN, Sam .The making of global capitalism: The political economy of American empire. Nova Iorque/Londres: Verso, 2013.

PANITCH, Leo; KONINGS, Martijn. American empire and the political economy of global finance. Nova Iorque: Palgrave Macmillan, 2008.

PROTESS, Ben; HIRSCHFELD, Julie, 2017, Trump Moves to Roll Back Obama-Era Financial Regulations, The New York Time, New York, 3 feb. 2017. Disponível em: <https://www. nytimes.com/2017/02/03/business/dealbook/trump-congress-financial-regulations.html>. Acesso em: 08 ago. 2017.

SCARBOROUGH, Joe. Obama's 'friendship' with Wall Street. Politico. Arlington, 11 jul. 2011.
SERRANO, Franklin. Do ouro imóvel ao dólar flexível. Economia e Sociedade, Campinas, v.11, n.2, p.237-53, jul/dez. 2002.

STRANGE, Susan. States and markets. Londres: Pinter Publishers, 1988a.

STRANGE, Susan. The future of the American empire. Journal of International Affairs, Nova Iorque, v. 42, n. 1, p.1-17, 1988b.

TAVARES, Maria da Conceição. A retomada da hegemonia norte-americana. Revista de Economia Política, São Paulo, v.5, n.2, p.5-15, abr/jun. 1985.

VERNENGO, Matías. From capital controls to dollarization: American hegemony and the US dollar. In: VERNENGO, Matías. Monetary integration and dollarization: No panacea. Northampton: Edward Elgar Publishing Limited, p. 245258, 2006.

ZWAN, Natascha van Der. Making sense of financialization. Socio-economic Review, v. 12, n. 1, p.99-129, jan. 2014. 